\title{
Theophylline Stimulates Fetal Breathing Movements during Hypoxia
}

\author{
JOHN M. BISSONNETTE, A. ROGER HOHIMER, CONRAD R. CHAO, SHARON J. KNOPP, AND \\ NEIL F. NOTOROBERTO
}

Department of Obstetrics and Gynecology, Oregon Health Sciences University, Portland, Oregon 97201

\begin{abstract}
The respiratory responses to theophylline during normoxia and hypoxia were determined in 13 unanesthetized fetal sheep. Theophylline (plasma levels $\sim 111$ $\mu \mathrm{mol} / \mathrm{L}$ ) increased the incidence of fetal breathing movements measured over $120 \mathrm{~min}$ from $37.7 \pm 4.8 \%$ to $61.1 \pm$ $5.7 \%$ (SEM) in normoxic fetuses. In isocapnic hypoxia (arterial $\mathrm{O}_{2}$ tension $\sim 1.86 \mathrm{kPa}$ ), theophylline increased the incidence from $20.0 \pm 6.3$ to $52.0 \pm 6.1 \%$. Theophylline also resulted in an increase in the slope of inspiration during both normoxia and hypoxia. We conclude that adenosine modulates fetal respiratory drive during normoxia and hypoxia. (Pediatr Res 28: 83-86, 1990)
\end{abstract}

\section{Abbreviations}

ECOG, electrocorticogram

In unanesthetized fetal sheep, acute hypoxia causes a depression in the incidence of fetal breathing movements $(1,2)$. This response is present in fetuses as early as $75-95 \mathrm{~d}$ gestation $(3,4)$. Despite a number of investigations (5-9), a satisfactory explanation of the mechanisms involved in this response to hypoxia has not been forthcoming.

In vagotomized, glomectomized adult animals, the depressive response to hypoxia can be attenuated by the adenosine receptor antagonist theophylline (10). In addition, a long acting analog of adenosine $\left[\mathrm{N}^{6}\right.$ (L-2-phenylisopropyl) adenosine] causes respiratory depression in these preparations (11), and this effect can be reversed by theophylline (12). Similarly, in neonatal rabbits, phenylisopropyl adenosine results in depression of respiration, and this effect can be reversed with theophylline (13-15). Moss and Scarpelli (16) have shown that theophylline increases the fetal respiratory responses to $\mathrm{CO}_{2}$. Some of the fetuses studied were acidemic and hypoxic, but these authors did not specifically determine if the adenosine antagonist would reverse the hypoxic depression of fetal breathing movements. Smith et al. (17) produced prolonged fetal apnea by injecting i.v. phenylisopropyl adenosine into fetal sheep. Because the dose used resulted in a loss of low voltage electrocortical activity that is the permissive state for fetal respiratory activity (18), the specific effect on fetal breathing is difficult to evaluate.

Our studies were performed to determine if the respiratory response to hypoxia could be altered by pretreating the fetus with theophylline. Because theophylline has been shown to stimulate fetal respiration during normoxia (16), this poses a difficulty in interpreting an effect during hypoxia. However, we reasoned that if adenosine contributes to the respiratory depression seen with

Received November 14, 1989; accepted March 23, 1990.

Correspondence: John M. Bissonnette, M.D., Rm 426, Research Bldg., L-458, Oregon Health Sciences University, Portland, OR 97201.

Supported by National Institutes of Health Grants HL-38039 and HD-10034. hypoxia, then the stimulatory effect of theophylline during hypoxia should be similar to that during normoxia. Although other studies indicate that theophylline does not cause a change in neonatal cerebral blood flow (19), we measured sagittal vein blood gases and $\mathrm{pH}$ to determine if these stimuli to the central chemoreceptors were altered.

\section{MATERIALS AND METHODS}

Thirteen pregnant ewes were used for these studies. Sterile surgery was carried out between 122 and 130 d gestational age under nitrous oxide and fluothane anesthesia in oxygen. The methods used for placement of catheters in the fetal trachea, axillary artery, sagittal vein, hind limb vein, and amniotic fluid and placement of electrodes above the dura have been described in detail (6). A polyvinyl catheter was inserted in the ewe's trachea and sutured to the s.c. tissues. This catheter was used for the addition of $\mathrm{N}_{2}$ and $\mathrm{CO}_{2}$ to the ewe's inspired air (20). The flow rates were $8-11 \mathrm{~L} / \mathrm{min}$ for nitrogen and $0.8-0.9 \mathrm{~L} / \mathrm{min}$ for $\mathrm{CO}_{2}$. After surgery, the animals were housed in $1.5 \times 3 \mathrm{~m}$ pens with free access to food and water.

Experiments were initiated 4-8 d after surgery and carried out over the following 2-6 d. The fetuses were between 127 and 142 $\mathrm{d}$ gestation at the time experiments were performed. The studies were conducted between 1000 and $1400 \mathrm{~h}$, a period during which we have not observed differences in the incidence of fetal breathing (21). The animals ate ad libitum during the studies. Four protocols were used, each consisting of a 2.5 -h period. For the normoxia studies, $0.9 \%$ saline $(15 \mathrm{~mL}$ bolus, followed by 0.5 $\mathrm{mL} / \mathrm{min}$ ) was infused into the fetal hind limb vein, after which air was added to the ewe's inspiratory flow. The theophylline protocol was similar to the normoxia except that the bolus infusion of saline and the subsequent constant infusion contained $27.8 \mathrm{mmol} / \mathrm{L}$ theophylline (Sigma Chemical Co., St. Louis, MO). The hypoxia and hypoxia theophylline protocols were similar to those described above except that $\mathrm{N}_{2}$ and $\mathrm{CO}_{2}$ were added to the ewe's inspiratory air at flow rates adjusted to decrease fetal arterial $\mathrm{PO}_{2}$ to less than $2.26 \mathrm{kPa}$ and maintain $\mathrm{PCO}_{2}$ at the control level. After the initial $0.5 \mathrm{~h}$ during which the blood theophylline levels were established and fetal blood gases stabilized, fetal respiratory variables were recorded for the next 120 min. Fetal blood was sampled for theophylline concentrations, $\mathrm{pH}$, and blood gases at 30 and $90 \mathrm{~min}$ of this 120 -min period. The order of the four protocols was chosen at random and only one protocol was used on a single day. A total of 38 experiments were carried out in the 13 animals. The pregnancy continued for 2-6 d after the last experiment in seven animals and the remaining six were killed because the four protocols were completed. No differences in results were seen between these two groups.

The tracheal, amniotic fluid, and arterial catheters were connected to pressure transducers (model $23 \mathrm{Db}$, Statham, Oxnard, CA) that were calibrated with a mercury manometer. The leads for the fetal ECOG were connected to an amplifier and filtered (0.5- to $30-\mathrm{Hz}$ band pass, Beckman type $9853 \mathrm{~A}$ coupler, Beck- 
man Instruments, Schiller Park, IL). The signals from the transducers and ECOG were displayed on a chart recorder (Beckman R611). The data were converted to digital form and stored for later analysis of the respiratory variables (model xT286, IBM Instruments, Inc., Danbury, CT). Fetal blood samples were analyzed for $\mathrm{pH}, \mathrm{PO}_{2}$, and $\mathrm{PCO}_{2}$ at $39^{\circ} \mathrm{C}$ with standard electrodes (Radiometer Ltd., Copenhagen). Fetal arterial and sagittal vein blood was sampled at 30 and 90 min of the 120-min study. Theophylline was measured in fetal blood at 30 and $90 \mathrm{~min}$ using a fluorescence polarization immunoassay (22). The coefficient of variation for this assay in our laboratory is $3 \%$.

Single-breath analysis of the respiratory variables was performed by methods similar to those of Wickham and Walker (23), although not in real time. Tracheal pressure and amniotic fluid pressure were digitized at $95 \mathrm{~Hz}$ and stored for later analysis. Amniotic pressure was subtracted from tracheal pressure; the difference was filtered digitally (Gaussian, cutoff frequency 2.85 $\mathrm{Hz}$ ) and subjected to a rule-based breath recognition algorithm. A breath was defined by the time and pressure at the initiation of an inspiratory effort and the time and pressure at the peak negative pressure. The initiation of a breath was considered to be the time and pressure that preceded negative rate of change of pressure that was at least $0.20 \mathrm{kPa}$ (taken over $50 \mathrm{~ms}$ ) and led to at least a $0.13 \mathrm{kPa}$ change in pressure. The inspiratory time was the time from initiation to peak negative pressure and breathto-breath interval the time from the initiation of one breath to the initiation of the next. Breath amplitude or depth was the difference between the initiation pressure and the peak negative pressure. Inspiratory slope was calculated by dividing amplitude by inspiratory time. Each breath was visually inspected before its parameters were included in the statistical analysis. Depending on the length (range $0.5-32 \mathrm{~min}$ ) of a breathing episode, 1-5 separate min representative of the episode were selected for breath-to-breath analysis. Each breathing episode during the 120 min had a portion analyzed. The median number of breaths analyzed in each protocol was 340 with a range of $118-559$. The lower number was from a single hypoxia saline study in which the incidence of breathing movements was only $4 \%$. The arithmetic means for each experiment were used to calculate respiratory parameters.

Fetal breathing movements were defined as repeated transient negative pressures recorded from the trachea (relative to amniotic fluid pressure) that were greater than $0.13 \mathrm{kPa}$ and occurred at a frequency $>0.25 \mathrm{~Hz}$. The incidence of fetal breathing movements was calculated as the percent of the 120 -min period during which breathing was present. Fetal ECOG was assessed visually into periods of low voltage $(<50 \mu \mathrm{V})$ and high voltage $(50-200 \mu \mathrm{V})$. The incidence of low voltage ECOG was similarly calculated.

All data are reported as the means \pm SEM. The incidence of fetal breathing movements and the respiratory variables for the four experimental situations were compared by one way analysis of variance. Significant differences between groups were determined by the least significant difference test (24).

\section{RESULTS}

The fetal arterial blood gases and $\mathrm{pH}$ for the four protocols are shown in Table 1. Control blood gases and $\mathrm{pH}$ obtained before infusing gases in the maternal trachea or fetal i.v. infusions were not different among the four groups before beginning the protocols. Theophylline at concentrations of $112.2 \pm 8.9 \mu \mathrm{mol} /$ $\mathrm{L}$ in fetal arterial blood did not cause any changes in arterial blood gases or $\mathrm{pH}$. The theophylline levels at 30 and $90 \mathrm{~min}$ of the study were not different. Hypoxia induced by adding $\mathrm{N}_{2}$ and $\mathrm{CO}_{2}$ to the ewe's inspired air resulted in a $0.93 \mathrm{kPa}$ fall in arterial $\mathrm{O}_{2}$ tension in both the fetuses infused with saline and those that received theophylline. Fetal arterial theophylline concentrations $(103.3 \pm 6.7 \mu \mathrm{mol} / \mathrm{L})$ in the fetuses that were then rendered hypoxic were similar to that achieved in the normoxia group. There were no differences in arterial $\mathrm{CO}_{2}$ tension and $\mathrm{pH}$ between the four groups. Table 2 lists the $\mathrm{O}_{2}$ and $\mathrm{CO}_{2}$ tensions and $\mathrm{pH}$ in the sagittal vein for the four experimental conditions. As for fetal arterial measurements, hypoxia produced significant decreases in sagittal vein $\mathrm{PO}_{2}(\sim 0.60 \mathrm{kPa})$, but theophylline had no effect; sagittal vein $\mathrm{PCO}_{2}$ and $\mathrm{pH}$ were unchanged under all conditions.

In studies in which fetuses were pretreated with theophylline, the incidence and depth of fetal breathing movements were increased. This occurred in both normoxia and hypoxia (Table $3)$. Although the incidence of breathing was less in hypoxia theophylline experiments than in normoxia theophylline, this difference was not significant. Respiratory timing was not affected by theophylline. Theophylline caused a significant increase in inspiratory slope during both normoxia and hypoxia. As was observed for the incidence of fetal breathing movements, the difference in inspiratory slope was not significant between normoxia theophylline and hypoxia theophylline. In the normoxia experiments, the fetuses spent $58.6 \pm 2.8 \%$ time in low voltage electrocortical activity, and this was unaffected by hypoxia $(56.2$ $\pm 2.4 \%)$. Theophylline pretreatment was associated with an insignificant increase to $67.4 \pm 2.7 \%$ during normoxia and 65.1 $\pm 2.9 \%$ during hypoxia.

\section{DISCUSSION}

Previous studies have examined a number of mechanisms concerning the depression in respiration seen with hypoxia in the fetus. The response is present in fetuses that have been subjected to peripheral chemodenervation (5). Fetal cerebral metabolism does not change during the moderate levels of hypoxia that result in respiratory depression (6), although it is not possible to determine the metabolic rate of the medulla itself. Transection of the fetal brain stem at various levels suggests that there is an area rostral to the pons, but caudal to the hypothalamus, that is involved in the hypoxic depression $(7,8)$. Further studies with smaller bilateral lesions have localized this area to the upper lateral pons (8), although these lesions do not define whether nuclei at the site or fiber tracts running through it are responsible. In addition, these lesion studies do not establish a neurochemical mechanism for the hypoxic depression.

In our experiments, sagittal vein $\mathrm{pH}$ and $\mathrm{PCO}_{2}$ were unchanged with theophylline pretreatment in both the normoxic and hypoxic studies. Therefore, a differential stimulus to central chemoreceptors cannot be invoked to explain the stimulatory effects of theophylline. In addition, the level of central hypoxia was similar in the control and theophylline studies. Theophylline produced a much greater increase in the incidence of fetal breathing movements during hypoxia than during normoxia. Because adenosine is released during hypoxia, this observation is consistent with theophylline's action as an antagonist to adenosine receptors. Theophylline concentrations of $50 \mu \mathrm{mol} / \mathrm{L}$ produce minimal inhibition of intracellular phosphodiesterase activity (25). Because at least half of the drug is bound (25), the plasma levels of free theophylline in our studies would have been about $50 \mu \mathrm{mol} / \mathrm{L}$, and it is unlikely that the major site of action was at the level of phosphodiesterase activity.

Previous studies $(26,27)$ have shown that the inspiratory slope of tracheal pressure increases as a linear function of arterial $\mathrm{CO}_{2}$ tension in fetal sheep. In our experiments, theophylline resulted in an increase in this parameter of respiratory drive in both normoxic and hypoxic fetal sheep. Hypoxia resulted in no change in inspiratory slope or depth of inspiration in agreement with earlier observations $(3,27)$. Our observation of no change in the components of the respiratory cycle with hypoxia was consistent with the observations of Sameshima and Koos (28), although other studies $(3,4)$ have reported a fall in respiratory rate.

Responses to theophylline in various parameters of respiratory activity have been variable. Moss and Scarpelli (16), in studies of fetal sheep, noted an increase in both frequency and tracheal deflection at $100 \mathrm{~ms}$. Lagercrantz et al. (13) noted an increase in 
Table 1. Fetal arterial blood gases and $\mathrm{pH}^{*}$

\begin{tabular}{|c|c|c|c|c|}
\hline & Normoxia saline & $\begin{array}{l}\text { Normoxia } \\
\text { theophylline }\end{array}$ & Hypoxia saline & $\begin{array}{c}\text { Hypoxia } \\
\text { theophylline }\end{array}$ \\
\hline \multicolumn{5}{|l|}{$\mathrm{PaO}_{2}(\mathrm{kPa})$} \\
\hline Control & $2.90 \pm 0.05$ & $2.73 \pm 0.09$ & $2.70 \pm 0.12$ & $2.65 \pm 0.11$ \\
\hline $30 \mathrm{~min}$ & $2.82 \pm 0.09$ & $2.69 \pm 0.09$ & $1.88 \pm 0.13 \dagger$ & $1.82 \pm 0.07 \dagger$ \\
\hline $90 \mathrm{~min}$ & $2.77 \pm 0.08$ & $2.67 \pm 0.11$ & $1.92 \pm 0.09 \dagger$ & $1.86 \pm 0.13 \dagger$ \\
\hline \multicolumn{5}{|c|}{$\mathrm{PaCO}_{2}(\mathrm{kPa})$} \\
\hline Control & $6.53 \pm 0.15$ & $6.50 \pm 0.11$ & $6.46 \pm 0.11$ & $6.29 \pm 0.17$ \\
\hline $30 \mathrm{~min}$ & $6.45 \pm 0.17$ & $6.40 \pm 0.13$ & $6.24 \pm 0.13$ & $6.05 \pm 0.17$ \\
\hline $90 \mathrm{~min}$ & $6.48 \pm 0.20$ & $6.37 \pm 0.15$ & $6.22 \pm 0.16$ & $6.06 \pm 0.19$ \\
\hline \multicolumn{5}{|l|}{$\mathrm{pHa}$} \\
\hline Control & $7.38 \pm 0.01$ & $7.37 \pm 0.01$ & $7.37 \pm 0.01$ & $7.36 \pm 0.01$ \\
\hline $30 \mathrm{~min}$ & $7.37 \pm 0.01$ & $7.36 \pm 0.01$ & $7.37 \pm 0.01$ & $7.36 \pm 0.01$ \\
\hline $90 \mathrm{~min}$ & $7.37 \pm 0.01$ & $7.37 \pm 0.01$ & $7.36 \pm 0.01$ & $7.35 \pm 0.01$ \\
\hline
\end{tabular}

* All values mean \pm SE. $n=11$ for normoxia saline and normoxia theophylline and $n=8$ for hypoxia saline and hypoxia theophylline. PaO 2 . arterial $\mathrm{O}_{2}$ tension; $\mathrm{PaCO}_{2}$, arterial $\mathrm{CO}_{2}$ tension; $\mathrm{pHa}$, arterial $\mathrm{pH}$. The control samples were obtained before beginning tracheal infusions in the ewe or i.v. infusions in the fetus. The 30- and 90-min samples were obtained 30 and 90 min after the desired fetal blood gases had been obtained.

$\dagger p<0.05$ compared with normoxia saline.

Table 2. Fetal sagittal vein blood gases and $\mathrm{pH}^{*}$

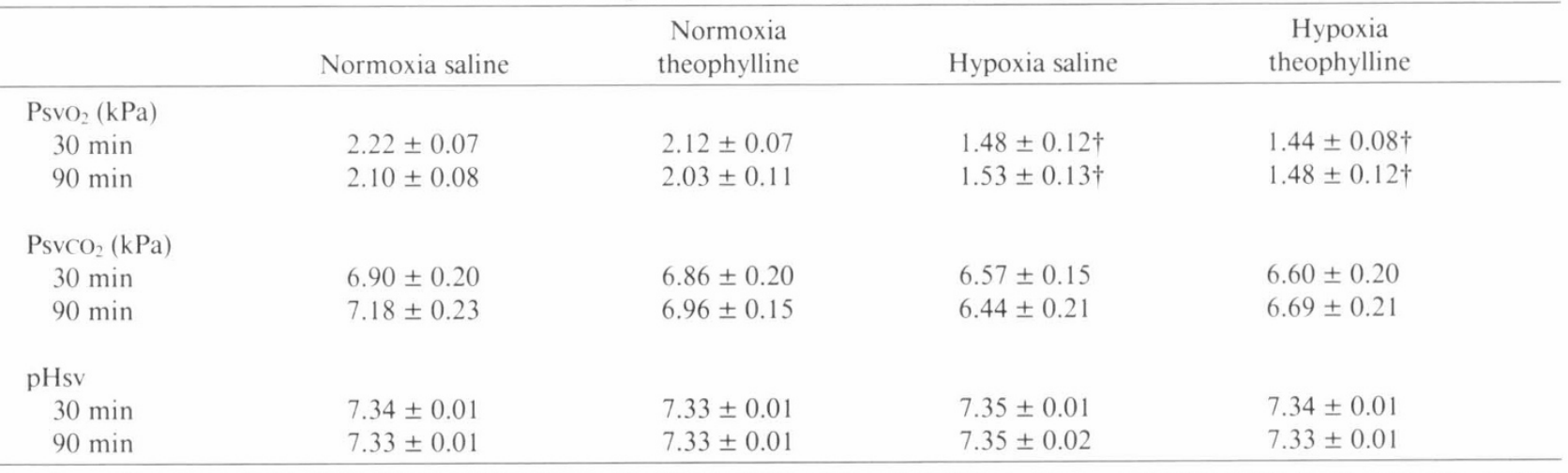

* Number of experiments as in Table 1. Time of blood sampling ( 30 and $90 \mathrm{~min})$ as in Table $1 . \mathrm{PsvO}_{2}$, sagittal vein $\mathrm{O}_{2}$ tension; $\mathrm{PvCO}$, sagittal vein $\mathrm{CO}_{2} ; \mathrm{pHsv}$, sagittal vein $\mathrm{pH}$.

$\dagger p<0.05$ compared to normoxia saline.

Table 3. Respiratory variables in fetal sheep during four experimental conditions*

\begin{tabular}{lcccc}
\hline & Normoxia saline & $\begin{array}{c}\text { Normoxia } \\
\text { theophylline }\end{array}$ & Hypoxia saline & $\begin{array}{c}\text { Hypoxia } \\
\text { theophylline }\end{array}$ \\
\hline Fetal breathing movements $(\%)$ & $37.7 \pm 4.8$ & $61.1 \pm 5.7 \dagger \ddagger$ & $20.0 \pm 6.3 \dagger$ & $52.0 \pm 6.1 \ddagger$ \\
$T_{i}(\mathrm{~s})$ & $0.32 \pm 0.03$ & $0.36 \pm 0.01$ & $0.38 \pm 0.05$ & $0.38 \pm 0.03$ \\
$\mathrm{~T}_{\text {tot }}(\mathrm{s})$ & $0.75 \pm 0.08$ & $0.86 \pm 0.06$ & $0.87 \pm 0.14$ & $0.98 \pm 0.10$ \\
Depth $(\mathrm{kPa})$ & $0.41 \pm 0.03$ & $0.76 \pm 0.07 \dagger \ddagger$ & $0.40 \pm 0.04$ & $0.63 \pm 0.07 \dagger \neq$ \\
Inspiratory slope $(\mathrm{kPa} / \mathrm{s})$ & $1.53 \pm 0.23$ & $2.30 \pm 0.23 \dagger \ddagger$ & $1.20 \pm 0.09$ & $1.85 \pm 0.24 \ddagger$
\end{tabular}

* Number of experiments as in Table $1 . \mathrm{T}_{\mathrm{i}}$, inspiratory time. $\mathrm{T}_{\text {tot }}$, breath-to-breath interval.

$\dagger p<0.05$ compared with normoxia saline.

$\ddagger p<0.05$ compared with hypoxia saline.

respiratory rate but no change in tidal volume in newborn rabbits, whereas Eldridge et al. (11) reported a small increase in frequency and a large increase in phrenic nerve output in adult cats. Direct comparisons cannot be made, inasmuch as the above studies involved either anesthesia or anesthesia and peripheral chemodenervation. In unanesthetized fetal sheep, we have found an increase in inspiratory slope and no change in respiratory rate.

The site of action of theophylline is an unsettled question. In an extensive set of experiments, Eldridge et al. (29) eliminated muscular and mechanical factors, carotid body and vagal re- flexes, spinally mediated mechanisms arising below the 7th cervical vertebra, changes in arterial $\mathrm{CO}_{2}$ or medullary extracellular fluid hydrogen ion concentration, and changes of whole body metabolic rate or release of substances from the adrenal glands. They concluded that the neural respiratory response to theophylline is mediated at the level of the brainstem. Because both a dopamine receptor antagonist and an inhibitor of dopamine biosynthesis reduced but did not abolish the stimulatory effects of aminophylline (29), Eldridge et al. conclude that dopamine is involved in the respiratory responses to the methylxanthines. The stable sagittal vein $\mathrm{CO}_{2}$ tension measurements obtained in 
our studies indicate that altered $\mathrm{CO}_{2}$ stimulus of respiratory centers is not responsible for the effects of theophylline. This would not have been expected, inasmuch as it has been shown in newborn piglets that theophylline does not alter cerebral blood flow in either normoxia or hypoxia (19). This increased respiratory drive at the same $\mathrm{CO}_{2}$ concentration is consistent with the left-shifted $\mathrm{CO}_{2}$ response after theophylline, which has been seen in fetal sheep (16) and premature human infants (30).

In adult male subjects, theophylline at plasma levels similar to those we obtained in fetal sheep caused a $21 \%$ increase in diaphragmatic contractility measured after stimulation of the phrenic nerve (31). We have observed a 50 and $54 \%$ increase in inspiratory slope during normoxia and hypoxia, respectively. Transdiaphragmatic pressure generated at functional residual capacity with bilateral electrical stimulation of the phrenic nerves to mimic a constant input to the diaphragm in air-breathing man cannot be directly compared with the slope of intrathoracic pressure deflections in the sheep fetus in utero. Nevertheless, the fact that a much greater change from control was observed after theophylline in our studies, coupled with the observations made concerning the central site of theophylline's actions (discussed above), is consistent with the conclusion that the effect is not confined to an improvement in diaphragmatic contractility.

Our studies have shown that theophylline stimulates fetal breathing movements during both normoxia and hypoxia. They also have implications about the adaptation that takes place when hypoxia is maintained in the fetus $(6,9)$. It may be that adenosine secretion in the CNS is not sustained or, alternately, that there is a down regulation of the adenosine receptors responsible for the inhibitory effects on respiration.

Note: After this manuscript was accepted for publication, a paper appeared (Koos BJ, Matsuda K 1990 Fetal breathing, sleep state, and cardiovascular responses to adenosine in sheep. J Appl Physiol 68:489-495) showing that theophylline stimulated the incidence of fetal breathing during hypoxia, although to a lesser extent than we have observed.

\section{REFERENCES}

1. Boddy K, Dawes GS, Fisher R, Pinter S, Robinson JS 1974 Foetal respiratory movements, electrocortical and cardiovascular responses to hypoxemia and hypercapnia in sheep. J Physiol (Lond) 243:599-618

2. Maloney JE, Adamson TM, Brodecky V, Dowling MH, Ritchie BC 1975 Modification of respiratory center output in the unanesthetized fetal sheep in utero. J Appl Physiol 39:552-558

3. Clewlow F, Dawes GS, Johnston BM, Walker DW 1983 Changes in breathing, electrocortical and muscle activity in unanesthetized fetal lambs with age. $\mathrm{J}$ Physiol (Lond) 341:463-476

4. Ioffe S, Jansen AH, Chernick V 1987 Maturation of spontaneous fetal diaphragmatic activity and fetal response to hypercapnia and hypoxemia. J Appl Physiol 62:609-622

5. Koos BJ, Sameshima H 1988 Effects of hypoxemia and hypercapnia on breathing movements and sleep state in sinoaortic-denervated fetal sheep. J Dev Physiol 10:131-144

6. Bissonnette JM, Hohimer AR 1987 Acute anemic hypoxemia produces a transient depression in fetal respiratory activity. J Appl Physiol 63:19421946

7. Dawes GS, Gardner WN, Johnston BM, Walker DW 1983 Breathing in fetal lambs: the effect of brain stem section. J Physiol (Lond) 335:535-553

8. Gluckman PD, Johnston BM 1987 Lesions in the upper lateral pons abolish the hypoxic depression of breathing in unanesthetized fetal lambs in utero. J Physiol (Lond) 382:373-383

9. Koos BJ, Kitanaka T, Matsuda K, Gilbert RD, Longo LD 1988 Fetal breathing adaptation to prolonged hypoxemia in sheep. J Dev Physiol 10:161-166

10. Millhorn DE, Eldridge FL, Kiley JP, Waldrop TG 1984 Prolonged inhibition of respiration following acute hypoxia in glomectomized cats. Respir Physiol 57:331-340

11. Eldridge FL, Millhorn DE, Kiley JP 1984 Respiratory effects of a long-acting analog of adenosine. Brain Res 301:273-280

12. Eldridge FL, Millhorn DE, Kiley JP 1985 Antagonism by theophylline of respiratory inhibition induced by adenosine. J Appl Physiol 59:1428-1433

13. Lagercrantz H, Yamamoto Y, Fredholm BB, Prabhakar NR, Von Euler C 1984 Adenosine analogues decrease ventilation in rabbit neonates. Theophylline stimulation of respiration via adenosine receptors? Pediatr Res 18:387390

14. Hedner T, Hedner J, Jonason J, Wessberg P 1984 Effects of theophylline on adenosine-induced respiratory depression in the preterm rabbit. Eur J Respir Dis 65:153-156

15. Runold M, Lagercrantz H, Fredholm BB 1986 Ventilatory effect of an adenosine analogue in unanesthetized rabbits during development. J Appl Physiol 61:255-259

16. Moss IR, Scarpelli EM 1981 Stimulatory effect of theophylline on regulation of fetal breathing movements. Pediatr Res 15:870-873

17. Smith KG, Pryor AL, Toubas PL, Seale TW, Sheldon RE 1986 Phenylisopropyl adenosine alters fetal electrocorticogram, breathing and heart rate. Dev Pharmacol Ther 9:1-11

18. Dawes GS, Fox HE, Leduc BM, Liggins GC. Richards RT 1972 Respiratory movements and rapid eye movement sleep in the foetal lamb. J Physiol (Lond) 220:119-143

19. McPhee AJ, Maxwell GM 1987 The effect of theophylline on regional cerebral blood flow responses to hypoxia in newborn piglets. Pediatr Res 21:573-578

20. Gleed RD, Poore ER, Figueroa JP, Nathanielsz PW 1986 Modification of maternal and fetal oxygenation with the use of tracheal gas infusion. Am J Obstet Gynecol 155:429-435

21. Hohimer AR, Bissonnette JM 1981 Effect of metabolic acidosis on fetal breathing movements in utero. Respir Physiol 43:99-106

22. Jolley ME, Stroupe SD, Schwenzer KS 1981 Fluorescence polarization immunoassay. An automated system for therapeutic drug determination. Clin Chem 27:1575-1579

23. Wickham PJD, Walker DW 1987 Analysis of fetal breathing in real time using a microprocessor. Am J Physiol 62:1733-1739

24. Snedecor GW, Cochran WH 1980 Statistical Methods, 7th Ed. Iowa State University Press, Ames

25. Rall TW 1982 Evolution of the mechanism of action of methylxanthines: from calcium mobilizers to antagonists of adenosine receptors. Pharmacologist $24: 277-287$

26. Moss IR, Scarpelli EM 1979 Generation and regulation of breathing in utero: fetal $\mathrm{CO}_{2}$ response test. J Appl Physiol 47:527-531

27. Dawes GS, Fox HE, Leduc BM, Liggins GC, Richards RT 1982 Effects of hypercapnia on tracheal pressure, diaphragm and intercostal electromy. ograms in unanesthetized fetal lambs. J Physiol (Lond) 326:461-474

28. Sameshima H, Koos BJ 1986 Effects of moderate hypoxia on fetal electrocortical activity, eye movements, and breathing activity in sheep. J Dev Physiol $8: 411-419$

29. Eldridge FL, Millhorn DE, Waldrop TG, Kiley JP 1983 Mechanism of respiratory effects of methylxanthines. Respir Physiol 53:239-261

30. Gerhardt T, McCarthy J, Bancalari E 1979 Effect of aminophylline on respiratory center activity and metabolic rate in premature infants with idiopathic apnea. Pediatrics 63:537-542

31. Murciano D, Aubier M, Viires N, Mal H, Pariente R 1987 Effects of theophylline and enprofylline on diaphragmatic contractility. J Appl Physiol 63:5157 